\title{
SOCIAL-PSYCHOLOGICAL FEATURES OF THE FORMATION OF PERSONALITY TRAITS IN CREATIVE THINKING IN ADOLESCENTS
}

\author{
Tukhtakhon Gaynazarovna Suleymanova \\ Doctor of Philosophy in Psychology, Assistant-Professor at the department of "General Psychology" \\ of Andizhan State University, Andizhan region, Republic of Uzbekistan
}

Article DOI: https://doi.org/10.36713/epra7870 DOI No: 10.36713/epra7870

\begin{abstract}
The article discusses scientific approaches to the social psychological features of the formation of creative thinking skills in adolescents. The components and results of experimental trials on the development of creative thinking in adolescents were also analyzed. Besides, in the research has shown that the formation of independent creative thinking skills in adolescents, who are the future of any state, is one of the important factors in the development of society. Creativity allows teenagers to be creative, not to be afraid of responsibility in making unconventional decisions, to be able to encourage their own thoughts and opinions.
\end{abstract}

KEY WORDS: creativity, sociality, creativity, novelty, responsibility, semantic flexibility, symbolic adaptive flexibility, originality.

\section{INTRODUCTION}

In the context of the huge changes taking place in our country and the acceleration of technical progress, innovations in various fields, huge reforms, the demand for creative people is growing. That is why the formation of independent creative thinking skills in adolescents, who are the future of any state, is one of the important factors in the development of society. Creativity allows teenagers to be creative, not to be afraid of responsibility in making unconventional decisions, to be able to encourage their own thoughts and opinions.

\section{METHODS}

Creativity (Latin, "create" - to create, "creative", creator) - means the creative ability of the individual, which characterizes the readiness to produce new ideas and is part of the talent as an independent factor. A person's creativity is manifested in his thinking, communication, emotions, certain types of activities [1]. Creativity characterizes a person as a whole or its specific features, mental acuity. Creativity is also reflected as an important factor in a person's ability. The term creativity was coined by in the 1950s. Introduced by $\mathrm{Dj}$. Gilford and Dj Gilford emphasizes that personal creativity consists of 4 main features [2]
1. Uniqueness, inconsistency in the expression of ideas, the pursuit of innovation $\mathrm{A}$ creative person strives to express his independent opinion, which differs from the opinion of others in different situations.

2. Semantic flexibility, that is, the perception of an object from a new perspective, the ability to evaluate new possibilities in it.

3. Symbolic adaptive flexibility, ie changing the perceptual properties of the object under study by understanding its new hidden aspects

4. Semantic spontaneous flexibility, the ability to repeat different ideas in order to study an object in uncertain situations

\section{RESULTS AND DISCUSSIONS}

According to American psychologist $\mathrm{P}$. Torrens, creativity is a problem or the advancement of scientific hypotheses; test and change the hypothesis; problem identification based on decision formulation; represents the sensitivity to the interdependence of knowledge and practical actions in finding a solution to a problem [3]. Like any other personality trait, creativity does not form all at once. Creativity does not develop spontaneously in adolescents, as it does in all individuals who are consistent at certain stages. Accordingly, research 
highlights a number of ways to successfully develop creative qualities in the individual.

The formation of a creative person can be defined as the development of a person in terms of creative activity and the creation of creative products that are performed in a mutually compatible way. The speed and scope of this process depends on biological and social factors, the activity and creative qualities of the individual, as well as the existing conditions, vital and professionally conditioned events. This was followed by Bronson, Merriyman (2010), Ken Robinson (2007), Fisher, Frey (2008), Begetto, Kaufman (2013), Ali (2011), Treffinger (2008), and b. Many studies conducted by, their results can be seen.

According to Ken Robinson, "creativity is a set of original ideas with their own value" (Azzam, 2009). Gardner explains the concept in his research: "Creativity is a practical action performed by a person, which must reflect a certain innovation and have a certain practical value." [1]

In terms of Emebayl's (1989) approach, creativity means "having a high level of unconventional skills as well as thorough knowledge of a particular field." Many studies have differing views on the relationship between intelligence and creativity. While one group of researchers argues that there is no correlation between them, representatives of the second group argue that the level of creativity and intelligence are interrelated (Kim, 2005).

According to Patti Drapeau, creative thinking is, first and foremost, comprehensive thinking on a particular issue. Comprehensive thinking requires adolescents to rely on many ideas in the performance of a learning task, problem, and task. In contrast, one-sided thinking is based on a single correct idea. One cannot deny one-sided and multi-sided thinking on the basis of information obtained in the process of thinking. Consequently, one-sided and all-round thinking plays an equal role in shaping creativity. That is, in completing the task, the teenager seeks several options for solving the problem (multi-faceted thinking), and then stops at only one correct solution that guarantees the most optimal result (one-sided thinking). Based on the above, the concept of "creativity" can be interpreted as follows: A person's creativity is manifested in his thinking, communication, emotions, certain types of activities. Creativity describes a person as a whole or its specific characteristics. [4].
The test, founded by E.P. Torrens in 1987 and measures a person's ability to think creatively, provides an opportunity to assess a person's creativity and its level on such criteria as activity in the organization of creative activity, quick thinking, originality and perfection. The answers to the questions suggested by the adolescent should meet exactly these four criteria. According to E.P. Torrens, the concept of "creativity" is based on the following: [1].

Creativity is a creative ability that characterizes an individual's readiness to produce new ideas and is an integral part of an individual's talent and includes: hypotheses;

- put forward a problem or scientific

- check and change the hypothesis;

- identify the problem based on the formation of the results of the decision;

- sensitivity to the contradiction between knowledge and practical actions in finding a solution to a problem

Creative thinking can be clearly reflected in any social sphere [4]

1) Students studying in a creative environment gradually develop an interest in performing creative tasks, as well as not to ignore questions, shortcomings and conflicting information as a result of observing a teacher with creative thinking;

2) to try to identify problems, to try to find solutions based on the assumptions made.

A person's creativity is manifested in his thinking, communication, emotions, certain types of activities. Creativity describes a person as a whole or its specific characteristics. Adolescents with creative thinking: $[1,3]$ thought of;

- expresses ideas that other peers have not themselves;

- chooses a specific way of expressing questions;

sometimes asks irrelevant or unusual

- enjoys tasks that remain open;

- prefers to discuss ideas on the basis of concrete evidence;

- chooses an unconventional approach to solving the problem. Individual creative qualities are as follows [1] 
ISSN (Online): 2455-3662

EPRA International Journal of Multidisciplinary Research (IJMR) - Peer Reviewed Journal

Volume: 7 | Issue: 7 | July 2021|| Journal DOI: 10.36713/epra2013 || SJIF Impact Factor 2021: 8.047 || ISI Value: 1.188

\begin{tabular}{|l|l|l|}
\hline \multicolumn{3}{|c|}{ QUALITIES OF CREATIVE THINKING } \\
\hline creative orientation & ability to think logically \\
\hline erudition & & \\
\hline reflex ability & & \\
\hline risk taking & to fully demonstrate their creativity \\
\hline development of intuition & possess the speed of thinking \\
\hline innovative ability & the ability to advance original ideas \\
\hline the ability to make new decisions based on existing experience and knowledge \\
\hline
\end{tabular}

Creative thinking skills can be successfully formed in adolescents only by making creativity a daily habit. In this process, a thorough understanding of the content of the information they receive is important and the methods and tools used to assess creative thinking skills are important in making accurate and substantiated conclusions and decisions. Only in an environment of a creative nature can the content of the information that adolescents receive be able to understand the interaction and begin to think about it (Anderson et al., 2000).

The following factors hinder the development of creativity in an individual: [4] behavior;

1) avoidance of risk;

2) allowing rudeness in thinking and

3) underestimation of a person's imagination and imagination;

4) subordination to others;

5) In any case, think only of success

Demonstrate creative skills in adolescents

-Creative approach to information analysis;

- be active in creating new ideas;

- independent thinking

- be able to determine the nature and significance of the information received;

- be able to analyze the problem statement; problem;

- Development of a plan to solve the

- the use of effective methods in solving the problem (analysis, synthesis, induction, deduction, comparison, etc.); problem;

- be able to choose ways to solve the

- substantiation and re-examination of the correctness of the decision;

- Carrying out small research to solve the problem;
Thirty-two 14-year-old adolescents participated in experimental trials to study the characteristics of creative thinking in adolescents. Adolescents were divided into 16 control and experimental groups.

The study was conducted in 3 phases:

In the first stage, experimental work was carried out to determine the level of development of creative thinking in adolescents.

In the second stage, a correctional program to develop creative thinking skills was implemented with the members of the experimental group. performed

In stage 3 , repeat psychodiagnostics was

In the first part of the experimental work was conducted the method of EP Torrens "Complete the picture" to study the features of creative thinking. This subtest consisted of 3 parts: "Draw a picture", "Complete the shape" and "Repetitive lines". "Draw a picture" subtest "Teenagers were given 30 pairs of incomplete pictures" Subtitle of repeating lines. They were asked to draw a whole picture from 30 pairs of repeating lines.

The analysis of the results was carried out on 5 indicators: "Speed" "Creativity", "Development", "Resistance to the connecting lines", "Accuracy of thought", "Abstraction in the nomenclature".

The sum of the scores for each indicator is calculated. The sum of all indicators is divided by 5 . The result is an indicator of creative thinking by E.P. Torrens.

-30 and less - low;

- 30-34 - below the age;

- 35-39 - slightly below the age limit;

- 40-60 - in proportion to age;

- 61-65 - slightly higher than age;

- 66-70 - higher than the age; 
EPRA International Journal of Multidisciplinary Research (IJMR) - Peer Reviewed Journal

Volume: 7 | Issue: 7 | July 2021|| Journal DOI: 10.36713/epra2013 || SJIF Impact Factor 2021: 8.047 || ISI Value: 1.188

- 70 and higher - significantly higher than the age index [3].

Indicators from 0 to 39 points are lower than the age indicators of creative thinking
Figures from 40 to 60 are proportional

Values from 61 to 70 are high.

\section{CONTROL GROUP TEENAGERS E.P.TORRENS RESULTS OF "INCOMPLETE PICTURES" (IN POINTS))}

\begin{tabular}{|c|c|c|c|c|c|c|c|}
\hline \multirow[t]{2}{*}{ Examiners } & \multicolumn{5}{|c|}{ Indicators of creative thinking } & \multirow{2}{*}{$\begin{array}{l}\text { The sum } \\
\text { of the } \\
\text { points }\end{array}$} & \multirow[t]{2}{*}{ Total } \\
\hline & $\begin{array}{l}\text { Speed of } \\
\text { thinking }\end{array}$ & Creativity & $\begin{array}{c}\text { Flexibility of } \\
\text { thought }\end{array}$ & $\begin{array}{c}\text { Resistance } \\
\text { to short } \\
\text { circuits in } \\
\text { the image }\end{array}$ & $\begin{array}{c}\text { Accuracy } \\
\text { of } \\
\text { thought }\end{array}$ & & \\
\hline 1 & 25 & 28 & 20 & 18 & 50 & 141 & 29 \\
\hline 2 & 20 & 15 & 15 & 18 & 45 & 113 & 23 \\
\hline$\overline{3}$ & 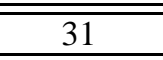 & 24 & 25 & $\overline{10}$ & 25 & 115 & 23 \\
\hline 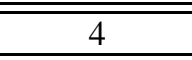 & 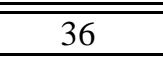 & 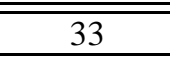 & 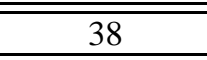 & 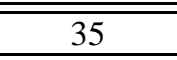 & 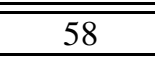 & 200 & $\overline{40}$ \\
\hline 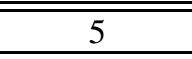 & 34 & 38 & 36 & 37 & 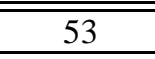 & 201 & 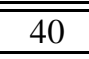 \\
\hline 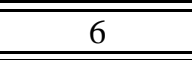 & 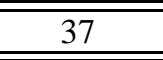 & $\overline{40}$ & $\overline{38}$ & $\overline{34}$ & 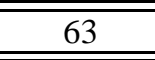 & 210 & $\overline{42}$ \\
\hline 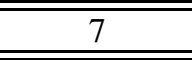 & 28 & 32 & 25 & 13 & 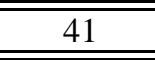 & 139 & 28 \\
\hline 8 & 35 & 37 & 40 & 42 & 53 & 207 & 41 \\
\hline 9 & 36 & 38 & 40 & 38 & 51 & 203 & 41 \\
\hline 10 & 22 & 20 & 25 & 14 & 32 & 1113 & 23 \\
\hline 11 & 26 & 24 & 28 & 15 & 25 & 118 & 24 \\
\hline$\overline{12}$ & 35 & 35 & 35 & 38 & 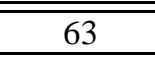 & 206 & 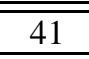 \\
\hline$\overline{13}$ & 35 & 28 & $\begin{array}{c}34 \\
\end{array}$ & 16 & 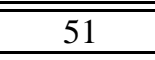 & 164 & 33 \\
\hline 14 & 30 & 24 & $\begin{array}{c}31 \\
\end{array}$ & 18 & 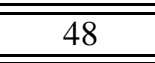 & $\overline{151}$ & 30 \\
\hline 15 & 24 & 26 & 25 & 10 & 31 & 116 & 23 \\
\hline 16 & 27 & 25 & 21 & 11 & 40 & 124 & 25 \\
\hline
\end{tabular}

According to the results of the "Complete the picture" method, a low level of creative thinking was detected in adolescents in the control group. 10 test takers: $(62 \%)$ with scores from 0 to 39.
Intermediate scores were found in 6 subjects $(38 \%)$. They had scores ranging from 40 to 60 points.

Adolescents in the control group did not have a high level of creative thinking (horse 61 to 70 points) $(0 \%)$

RESULTS OF TEENAGERS IN THE EXPERIMENTAL GROUP ON EP TORRENS METHODOLOGY "INCOMPLETE PICTURES:"

\begin{tabular}{|c|c|c|c|c|c|c|c|}
\hline \multirow[t]{2}{*}{ Examiners } & \multicolumn{5}{|c|}{ Indicators of creative thinking } & \multirow{2}{*}{$\begin{array}{c}\text { The } \\
\text { sum of } \\
\text { the } \\
\text { points }\end{array}$} & \multirow[t]{2}{*}{ Total } \\
\hline & $\begin{array}{c}\begin{array}{c}\text { Speed } \\
\text { of } \\
\text { thinking }\end{array}\end{array}$ & Creativity & $\begin{array}{l}\text { Flexibility } \\
\text { of thought }\end{array}$ & $\begin{array}{l}\text { resistance } \\
\text { to short } \\
\text { circuits in } \\
\text { the image }\end{array}$ & $\begin{array}{c}\text { Accuracy } \\
\text { of } \\
\text { thought }\end{array}$ & & \\
\hline$\overline{1} 1$ & 30 & 25 & 25 & 10 & 25 & 115 & 23 \\
\hline 2 & 32 & 37 & $\overline{34}$ & 36 & $\overline{52}$ & 191 & 38 \\
\hline 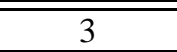 & 25 & 27 & 20 & $\overline{18}$ & 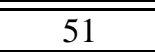 & 14141 & 29 \\
\hline 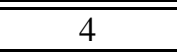 & 35 & 28 & 34 & $\overline{16}$ & $\overline{51}$ & 164 & 33 \\
\hline 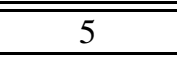 & 34 & 37 & 36 & 37 & $\overline{54}$ & 198 & 40 \\
\hline 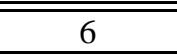 & 21 & 20 & 25 & $\overline{14}$ & 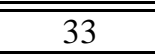 & $\overline{1113}$ & 23 \\
\hline 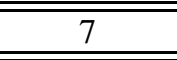 & 25 & 24 & 29 & $\overline{15}$ & 25 & 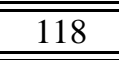 & 24 \\
\hline$\overline{88}$ & $\overline{35}$ & 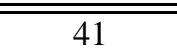 & 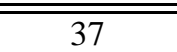 & 35 & 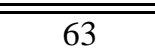 & 211 & 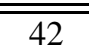 \\
\hline
\end{tabular}




\begin{tabular}{|c|c|c||c||c||c||c|c|}
\hline 9 & 32 & 23 & 25 & 10 & 25 & 115 & 23 \\
\hline \hline 10 & 38 & 35 & 36 & 38 & 57 & 204 & 41 \\
\hline \hline 11 & 25 & 26 & 25 & 10 & 30 & 116 & 23 \\
\hline \hline 12 & 28 & 25 & 20 & 11 & 40 & 124 & 25 \\
\hline \hline 13 & 35 & 34 & 36 & 38 & 63 & 206 & 41 \\
\hline \hline 14 & 30 & 31 & 24 & 13 & 41 & 139 & 28 \\
\hline \hline 15 & 37 & 34 & 37 & 34 & 60 & 202 & 40 \\
\hline \hline 16 & 27 & 28 & 20 & 18 & 48 & 141 & 29 \\
\hline
\end{tabular}

\begin{tabular}{|c|c|c|c|c|}
\hline $\begin{array}{c}\text { The level of development } \\
\text { of creative thinking }\end{array}$ & \multicolumn{2}{|c|}{ Control group } & \multicolumn{2}{c|}{ Experimental group } \\
\hline & Number & Percent & Number & Percent \\
\hline Low level & 10 & 62 & 11 & 69 \\
\hline Intermediate level & 6 & 38 & 5 & 31 \\
\hline High level & 0 & 0 & 0 & 0 \\
\hline
\end{tabular}

Adolescents in both groups had a low level of development of creative thinking. 10 subjects $(62 \%)$ in the control group and 11 subjects $(69 \%)$ in the experimental group scored from 0 to 39 points.

According to the E P Torrens method, low results mean inertia of the subjects, lack of motivation for creative thinking, inability to move from one task to another, difficulty in developing new ideas from the usual thinking, the development of the content and essence of the problem

The average level of creative thinking was recorded in 6 adolescents in the control group (38\%) and 5 adolescents in the experimental group (31\%). A high level of development of creative thinking was not observed in the control group or in the experimental group. Based on the initial psychological diagnosis, a low level of development of creative thinking was identified in the subjects of both groups. These subjects used simple, homogeneous images (fruits, vegetables, utensils, etc.) to perform the method. These images were simple and described what the teenagers saw justified the need to be carried out.

The psychocorrection program for the development of creative thinking in adolescents consists of 3 parts using the design method, which consists of diagnostic, correctional developmental and evaluation of the effectiveness of the results.

The correction program is designed for 6 weeks and the duration of each session is 35-40 minutes. Classes include a variety of activating techniques for working with adolescents: brainstorming, discussion, conversation, creative work, project presentation.

In order to determine the effectiveness of the program, the experiment was conducted at the critical stage of the trial.

This result was reflected in the fact that the subjects who participated in the psychocorrectional program were quick to perform tasks, generalize, analyze and synthesize information and make unusual decisions.

Based on the results of the subtest "Complete the picture", it was found that the subjects in the control group had a low level of independent and creative thinking: 9 subjects $(56 \%)$ had a score from 0 to 39 points.

Currently, the average level of development of independent and creative thinking was determined in 7 subjects $(44 \%)$. These subjects had scores ranging from 40 to 60 points. A high score of 61 to 70 points was not detected in the control group $(0 \%)$.

Comparative analysis of the results of repeated psychodiagnostics on the subtests "Take a picture" by P. Torrens of the control and experimental group.

\begin{tabular}{|c|c|c|c|c|}
\hline $\begin{array}{c}\text { The level of development } \\
\text { of creative thinking }\end{array}$ & \multicolumn{2}{|c|}{ Control group } & \multicolumn{2}{c|}{ Experimental group } \\
\hline & Number & Percent & Number & Percent \\
\hline Low level & 9 & 56 & 6 & 38 \\
\hline Intermediate level & 7 & 44 & 10 & 62 \\
\hline High level & 0 & 0 & 5 & 31 \\
\hline
\end{tabular}


This result was reflected in the fact that the subjects who participated in the psychocorrectional program were able to make unusual decisions on the assignments faster, generalize, analyze and synthesize information.

\section{CONCLUSION}

The performance of tasks in the psychocorrectional program, conducted using the design method, was of great importance for the demonstration of positive changes in the subjects of the experimental group on the development of creative thinking. In the formation of creativity as a personality trait, the individual psychological characteristics of the adolescent, the social situation, the use of innovative methods in education, the use of democratic methods in interpersonal relationships between adolescents and teachers, respect for adolescent personality and individuality, support for new unconventional decisions.

\section{REFERENCES}

1. Bashina T.F., Ilyin E.P. Psychology of creativity, creativity, giftedness. - SPb .: Peter, 2009.

2. D.S. Gavrilov Psychology of creativity University education 2003.

3. Druzhinin Vladimir Nikolaevich (Doctor of Psychology) Psychology of general abilities (Concept of creativity by J. Guildford and E.P. Torrance)

4. Drapeau Patti. Sparking student creativity (practical ways to promote innovative thinking and problem soving). - Alexandria - Virginia, USA: ASCD

5. Development of creative thinking in the system of additional education for children and adults Young scientist. - 2016. - No. 6 (110). 